\title{
African genes tracked back
}

Method extends archaeological and linguistic data by tracing early human migration.

\section{BY ERIKA CHECK HAYDEN}

$\mathrm{T}$ he first humans left Africa some 200,000 years ago, dispersing to populate the rest of the world. But this was not a one-way trip: some people came back. Scientists say that they have traced a reverse migration that, in two steps, carried genes from the rest of the world back to southern Africa, long before European colonizers arrived.

The findings are part of a flurry of research enabled by better tools to survey African genomes. For the first time, population geneticists can examine the complex history of human migration in Africa effectively, a field long dominated by the analysis of bones, artefacts and languages.

"Up until now this was mostly done based on linguistics and archaeology, and now we can use genetics to test ideas," says Carina Schlebusch, a geneticist at Uppsala University in Sweden. "It's a really exciting time for African genetics."

Genetic signs of reverse migrations had been spotted before. Over the past decade, evidence has accrued that people returned to Africa after the original 'out of Africa' event. And more recently, DNA data suggest that a small group of east Africans migrated to southern Africa to mix with the hunter-gatherers who lived there 2,000 years ago.

A new analysis connects these two migrations. In a paper posted on the preprint server arXiv on 30 July, population geneticists at Harvard Medical School in Boston, Massachusetts, report their use of a method to identify traces of this two-step migration within DNA of the minority Khoe-San ethnic groups of southern Africa (J. K. Pickrell et al. Preprint at http:// arxiv.org/abs/1307.8014; 2013).

The researchers examined more than half a million sites of genetic variation in the genomes of around 1,000 people, including some 200 southern Africans representing 22 African groups. Turning to the Khoe-San, the team looked for regions of DNA in which individuals seemed to have inherited a chromosome from a different ethnic group at some time in the past.

These DNA regions contain blocks of genetic variants that are linked together in patterns similar to those seen in non-Khoe-San groups. The blocks are shorter and more scattered in the Khoe-San than in the presumed donor group, because the genetic recombination that occurs with each generation has, over time, fragmented the donated chromosome.

By measuring the extent of the fragmentation, the researchers could estimate how many

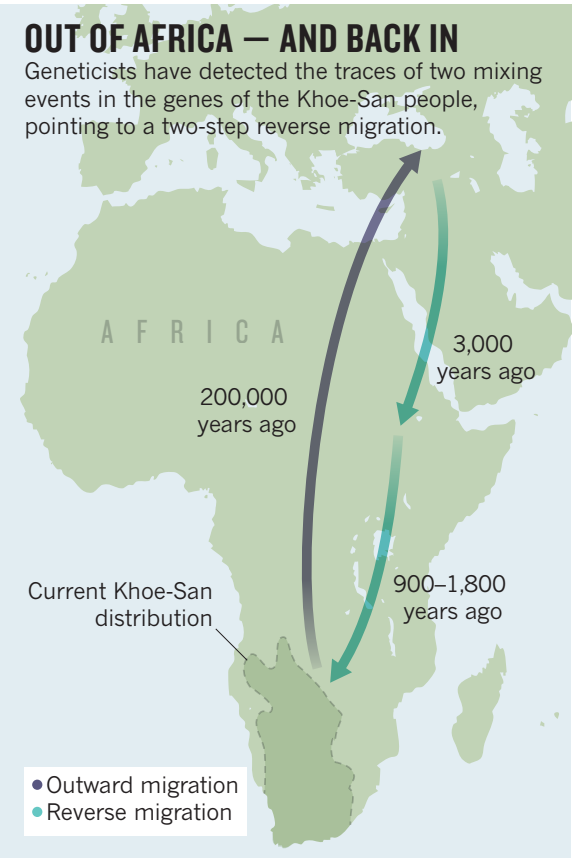

generations ago the chromosome had been introduced into Khoe-San genomes. They saw signs reflecting two waves of migration: one about 3,000 years ago, of non-Africans entering east Africa, and a second one $900-1,800$ years ago, as east Africans migrated to southern Africa and brought non-African genes along with them (see 'Out of Africa - and back in').

Because of this two-step migration, some Khoe-San groups who were thought to have been genetically quite isolated actually carry 1-5\% non-African DNA, report the study's authors, led by David Reich and postdoctoral fellow Joseph Pickrell.

Geneticists had already been able to detect past instances of 'admixture', or interbreeding, but this was the first time that multiple admixtures had been detected within a single group's genetic profile. "The most important finding is that this migration from east to south was a carrier for non-African genes," says Luca Pagani, a geneticist at the Wellcome Trust Sanger Institute near Cambridge, UK, who has studied reverse migration to Ethiopia.

The finding makes sense in light of previous archaeological and linguistic studies, says Sarah Tishkoff, a genetic anthropologist at the University of Pennsylvania in Philadelphia. For instance, southern African speakers of
DNATURE.COM For more on the out-of-Africa migration, visit: go.nature.com/sctdex
Khoe-Kwadi, a family of languages that traces its origins to east Africans who brought herding techniques to the south, had the highest proportion of non-African genes in the new study. Also, 2,000-year-old cattle and sheep bones and pottery characteristic of east African herding cultures have been found across southern Africa. "Perhaps this method could be applied to other cases where there isn't good archaeological data," says Tishkoff.

But the finding also raises questions about the identity of the eastern Africans who met the non-Africans, and of the non-Africans themselves. The non-African genes in the Khoe-San most closely resemble those found in modern southern Europeans. But the authors think it more likely that the carriers of those genes at the time actually crossed into Africa from the Middle East or the Arabian peninsula.

\section{ADVANCE ON A CHIP}

The research underscores the use of improved methods and richer data sets to explore the complex genetic history of Africa. Studies suggest that Africa is the most genetically diverse continent in the world and that the Khoe-San people have the world's oldest genetic lineages. They are thought to be descendants of the first people to split from the other modern humans who began the journey out of Africa.

Despite the region's outsize importance in human history, only in the past year has a significant amount of data on groups from all parts of Africa become available. Genomes of just a handful of the 2,000 African ethnic groups had previously been sequenced, partly because collecting DNA from remote African ethnic groups is an ethical and logistical challenge, and partly because most funding for genetic studies goes to medical, not anthropological, applications.

Compounding the problem, DNA microarrays designed to survey human genetic diversity were initially made to sample the variation seen in European and European-American genomes, and did not capture African diversity. That changed in 2011, when Reich and other geneticists worked with the company Affymetrix, based in Santa Clara, California, to design a gene chip - the Human Origins Array - that targets sites of variation seen in more diverse samples. Pickrell and Reich used the chip in their analysis, as have other surveys of African diversity.

That represents a welcome sea change, says Pagani. "Until now, we have been applying tools designed specifically for non-African people to African people." - 